\title{
Multidisciplinary learning in family planning clinics
}

\author{
Paula Baraitser, MBBS, BSc, MA, MFFP \\ Senior Clinical Medical Officer, Department of Family Planning, Community Health South London, St Giles Road, London, \\ $U K$
}

Mary Herns, SRN, BSc, MSc, PhD

Education Advisor, Department of Medical Education, Guys', St Thomas' and Kings Schools of Medical Education and Dentistry, Henrietta Raphael House, Guys' Hospital, London, UK

Sarah Webb

Staff Support and Development Administrator, Department of Family Planning, Community Health South London, St Giles Road, London, UK

(Accepted November, 1999)

\section{Key words}

inter-professional leaning, peer facilitation, staff development

\section{Key message points \\ - Joint learning between clinical and non-clinical members of family planning teams is an acceptable and effective approach to staff development \\ Peer facilitation encourages learning in multidisciplinary workshops}

\section{Introduction}

Health care is increasingly provided by multidisciplinary teams, and multidisciplinary learning has been suggested as a means to encourage effective teamworking. ${ }^{1-3}$

Interdisciplinary collaboration is particularly important in family planning, where the roles of different staff groups often overlap. For example, doctors prescribe, nurses issue to protocols, and receptionists/administrators dispense contraceptives. This process requires close collaboration and an understanding of the roles of each team member by all of the others. This study was based on the premise that inter-disciplinary training for all staff groups would encourage such collaboration.

Joint training programmes for doctors and nurses have been shown to be effective and acceptable in family planning, ${ }^{4}$ but the involvement of non-clinical staff presents new challenges. Since there is no culture of continuing training in this discipline, we were concerned that its sudden introduction might be perceived as a criticism of longstanding working practices. In addition it was a concern that existing hierarchies within and between disciplines might hinder collaborative learning.

The aim of this study was to evaluate the acceptability of joint learning between clinical and non-clinical members of family planning teams.

\section{Methods}

A multidisciplinary workshop was facilitated by non-expert facilitators comprising representatives from all disciplines who had received specific training. The workshop included sessions in which clinical and non-clinical staff learnt separately, and sessions in which they learnt together. Thus, doctors and nurses were offered training on sexual history taking in relation to the management of clients using intrauterine devices (IUDs), whilst receptionists and administrators were offered training on issues related to the maintenance of confidentiality within clinics. In the second part of the workshop all staff groups worked together to consider how effective teamwork might contribute to the efficient running of the clinics and the reduction of waiting times.

\section{Evaluation}

The programme was evaluated using a questionnaire documenting participants' experience of learning in multidisciplinary teams, a pre- and post-workshop selfassessment of knowledge, a self-assessment of the predicted and actual effect of the workshop on clinical practice, and telephone interviews with the facilitators.

\section{Results}

Most participants felt comfortable learning in multidisciplinary groups (Table 1). It was generally perceived to be an advantage that facilitators were not 'experts' since this generated an informal atmosphere in which participants felt able to express their views. In addition, the facilitators were familiar with the day-to-day challenges of family planning clinic work and were therefore able to ensure that what was learnt was relevant to this work. All doctors and nurses, and the majority of receptionists and administrators, felt that their knowledge had increased as a result of the workshops (Table 2), and predicted an effect on their clinical practice (Table 3).

Table 1 Positive/negative feelings in relation to learning in multidisciplinary teams

\begin{tabular}{llll}
\hline & $\begin{array}{l}\text { Doctors } \\
(\mathrm{n}=11)\end{array}$ & $\begin{array}{l}\text { Nurses } \\
(\mathrm{n}=20)\end{array}$ & $\begin{array}{l}\text { Admin/Recep } \\
(\mathrm{n}=16)\end{array}$ \\
\hline Comfortable & $100 \%$ & $89 \%$ & $81 \%$ \\
Interested & $75 \%$ & $89 \%$ & $94 \%$ \\
Confident & $58 \%$ & $32 \%$ & $56 \%$ \\
Listened to & $83 \%$ & $84 \%$ & $75 \%$ \\
Included & $67 \%$ & $74 \%$ & $81 \%$ \\
Motivated & $58 \%$ & $74 \%$ & $69 \%$ \\
Anxious & $9 \%$ & 0 & 0 \\
Bored & 0 & 0 & $6 \%$ \\
Embarrassed & 0 & $5 \%$ & 0 \\
Intimidated & 0 & 0 & 0 \\
Uncomfortable & 0 & 0 & $6 \%$ \\
Excluded & 0 & 0 & 0 \\
Silenced & 0 & 0 & 0 \\
\hline
\end{tabular}


Table 2 Average scores pre- and post-training for each staff group staff group

\begin{tabular}{llll}
\hline Staff group & $\begin{array}{l}\text { Mean } \\
\text { pre-training } \\
\text { score (range)* }\end{array}$ & $\begin{array}{l}\text { Mean post- } \\
\text { training } \\
\text { score (range)* }\end{array}$ & $\begin{array}{l}\text { Average change +/- } \\
\text { (range) }\end{array}$ \\
\hline $\begin{array}{l}\text { Doctors/Nurses } \\
\text { Admin/Reception }\end{array}$ & $46(19$ to 62$)$ & $\begin{array}{l}57(34 \text { to } 66) \\
54(32 \text { to } 60)\end{array}$ & $\begin{array}{l}+12(+1 \text { to }+38) \\
+8.5(-3 \text { to }+22)\end{array}$ \\
\hline
\end{tabular}

* Maximum score for doctors/nurses was 70 and for receptionists/ administrators was 60

The telephone interviews with the facilitators were largely favourable. Six of the 12 had encountered no difficulties, whilst the remainder (including representatives from all disciplines) each reported that one member of the group had tended to dominate the rest.

\section{Discussion}

Our results show that peer facilitated multidisciplinary learning for clinical and non-clinical staff together is an acceptable form of staff training for family planning teams. Almost all staff felt comfortable in their learning groups and few reported feeling constrained by inter- or intradisciplinary hierarchies. We feel that the exclusion of nonclinical staff from inter-disciplinary learning programmes
Table 3 The effect of the workshops on clinical practice

\begin{tabular}{llll}
\hline & Yes & No & No response \\
\hline $\begin{array}{l}\text { Immediately post-workshop } \\
\mathrm{n}=47(100 \%)\end{array}$ & $85 \%$ & $8.5 \%$ & $6 \%$ \\
$\begin{array}{l}\text { One month post-workshop } \\
\mathrm{n}=33(100 \%)^{*}\end{array}$ & $64 \%$ & $33 \%$ & $3 \%$ \\
\hline
\end{tabular}

* This represents a $70 \%$ response rate from the 47 participants

represents a missed opportunity for the exchange of ideas between family planning clinic teams.

\section{Acknowledgements}

We are grateful to Dr F Reader for advice during the initial stages of this project.

Statements on funding and competing interests

Funding. The staff development workshops were funded by Community Health South London NHS Trust.

Competing interests. The authors were responsible for running the staff development programme.

References

Parsell G, Bligh J. Interprofessional Learning. Postgraduate Medical Journal 1998; 74: 89-95. Parsell G, Bligh J. Educational Principles underpinning successful shared learning. Medica Teacher 1998; 20: 522-529.

Jones RVH. Getting better: education and the primary health care team. British Medical Journo 1992; 305: 506-508.

Reader F, Hunt K, Passmore H, Royce S, Adapa U. Professional development in reproductive and sexual health - a pilot study from Suffolk UK. British Journal of Family Planning 1999; 24 